\title{
Numerical solutions of the generalized Burgers-Huxley equation by implicit exponential finite difference method
}

\author{
B. INAN and A. R. BAHADIR
}

\begin{abstract}
In this paper, numerical solutions of the generalized Burgers-Huxley equation are obtained using a new technique of forming improved exponential finite difference method. The technique is called implicit exponential finite difference method for the solution of the equation. Firstly, the implicit exponential finite difference method is applied to the generalized Burgers-Huxley equation. Since the generalized Burgers-Huxley equation is nonlinear the scheme leads to a system of nonlinear equations. Secondly, at each time-step Newton's method is used to solve this nonlinear system then linear equations system is obtained. Finally, linear equations system is solved using Gauss elimination method at each time-step. The numerical solutions obtained by this way are compared with the exact solutions and obtained by other methods to show the efficiency of the method.
\end{abstract}

Mathematics Subject Classification 2010: 65N06, 35D99

Additional Key Words and Phrases: The generalized Burgers-Huxley equation, finite difference method, implicit exponential finite difference method.

\section{INTRODUCTION}

Most of the problems in various field as physics, chemistry, biology, mathematics and engineering modeled by nonlinear partial differential equations. One of the nonlinear partial differential equations is the generalized Burgers-Huxley equation. The generalized Burgers-Huxley equation of the form;

$$
\frac{\partial u}{\partial t}+\alpha u^{\delta} \frac{\partial u}{\partial x}-\frac{\partial^{2} u}{\partial x^{2}}=\beta u\left(1-u^{\delta}\right)\left(u^{\delta}-\gamma\right), 0 \leq x \leq 1, t \geq 0
$$

with the initial condition

$$
u(x, 0)=\left(\frac{\gamma}{2}+\frac{\gamma}{2} \tanh \left[A_{1} x\right]\right)^{\frac{1}{\delta}}
$$

and the boundary conditions

$$
u(0, t)=\left(\frac{\gamma}{2}+\frac{\gamma}{2} \tanh \left[-A_{1} A_{2} t\right]\right)^{\frac{1}{\delta}}
$$


and

$$
u(1, t)=\left(\frac{\gamma}{2}+\frac{\gamma}{2} \tanh \left[A_{1}\left(1-A_{2} t\right)\right]\right)^{\frac{1}{\delta}}
$$

The exact solution of Eq. (1) is

$$
u(x, t)=\left(\frac{\gamma}{2}+\frac{\gamma}{2} \tanh \left[A_{1}\left(x-A_{2} t\right)\right]\right)^{\frac{1}{\delta}}
$$

where

$$
\begin{aligned}
& A_{1}=\frac{-\alpha \delta+\delta \sqrt{\alpha^{2}+4 \beta(1+\delta)}}{4(1+\delta)} \gamma \\
& A_{2}=\frac{\gamma \alpha}{1+\delta}-\frac{(1+\delta-\gamma)\left(-\alpha+\sqrt{\alpha^{2}+4 \beta(1+\delta)}\right)}{2(1+\delta)}
\end{aligned}
$$

and $\alpha, \beta, \gamma$ and $\delta$ are parameters that $\beta \geq 0, \delta>0, \gamma \in(0,1)$. When $\alpha=0$ and $\delta=1$, Eq. (1) is reduced to the Huxley equation which describes nerve pulse propagation in nerve fibres and wall motion in liquid crystals[1]

$$
\frac{\partial u}{\partial t}-\frac{\partial^{2} u}{\partial x^{2}}=\beta u(1-u)(u-\gamma)
$$

When $\beta=0$ and $\delta=1$, Eq. (1) is reduced to the Burgers equation which describes the far field of wave propagation in nonlinear dissipative systems[1]

$$
\frac{\partial u}{\partial t}+\alpha u \frac{\partial u}{\partial x}-\frac{\partial^{2} u}{\partial x^{2}}=0
$$

It is known that nonlinear diffusion equations (6) and (7) play important roles in nonlinear physics. They are of special significance for studying nonlinear phenomena. If we take $\delta=1$ and $\alpha \neq 0, \beta \neq 0$, Eq. (1) becomes the following Burgers-Huxley equation:

$$
\frac{\partial u}{\partial t}+\alpha u \frac{\partial u}{\partial x}-\frac{\partial^{2} u}{\partial x^{2}}=\beta u(1-u)(u-\gamma) .
$$

Eq. (8) shows a prototype model for describing the interaction between reaction mechanisms, convection effects and diffusion transport. This equation was investigated by Satsuma in 1986[1].

In literature, many numerical methods have been proposed for approximating solution of the generalized Burgers-Huxley equation. Ismail et al.[2] solved the 
generalized Burgers-Huxley and Burgers-Fisher equations by using the Adomian decomposition method. Hashim et al.[3] used the decomposition scheme obtained from the Adomian decomposition method yields an analytical solution in the form of a rapidly convergent series for the numerical solutions of the generalized Burgers-Huxley equation. Javidi[4, 5] presented methods for solving of the equation by using the collocation formula for calculating spectral differentiation matrix for Chebyshev-Gauss-Lobatto point. Spectral collocation method and Darvishi's preconditionings to solve the generalized Burgers-Huxley equation was used by Darvishi et al.[6]. Batiha et al. [7] used the variational iteration method, which based on the incorporation of a general Lagrange multiplier in the construction of correction functional for the equation. Numerical solutions of the equation was obtained using a polynomial differential quadrature method by Sari and Gürarslan[8]. For numerical solution of the equation, based on collocation method using Radial basis functions, called Kansa's approach was used by Khattak[9]. Javidi and Golbabai[10] presented the spectral collocation method using Chebyshev polynomials for spatial derivatives and fourth order Runge-Kutta method for time integration to solve the generalized Burgers-Huxley equation. Biazar and Mohammadi[11] used the differential transform method for solution of the equation. A fourth order finite-difference scheme in a two-time level recurrence relation was proposed for the equation by Bratsos[12]. Dehghan et al. [13] found numerical solution of the generalized Burgers Huxley equation using three methods based on the interpolation scaling functions and the mixed collocation finite difference schemes. Çelik[14] used Haar wavelet method for solving the equation. El-Kady et al. [15] proposed based on cardinal Chebyshev and Legendre basis functions with Galerkin method for solution of the equation. The discrete Adomian decomposition method was applied to a fully implicit scheme of the generalized Burgers-Huxley equation by Al-Rozbayani[16]. Mittal and Tripathi[17] used the collocation of cubic B-splines method for numerical solution of the generalized Burgers-Fisher and generalized Burgers-Huxley equations. Chebyshev Wavelet collocation method for solving generalized Burgers-Huxley equation proposed by Çelik[18].

The explicit exponential finite difference method was originally developed by Bhattacharya for solving of the heat equation[19]. Bhattacharya[20] and Handschuh and Keith[21] used exponential finite difference method for the solution of Burgers equation. Bahadir solved the $\mathrm{KdV}$ equation by using the exponential finite difference technique[22]. Implicit exponential finite difference method and fully implicit exponential finite difference method was applied to the Burgers equation by Inan and 
Bahadir[23].

In this paper, we develop an implicit exponential finite difference scheme for solving the generalized Burgers-Huxley equation. In here, as different from the previous methods, implicit exponential finite difference method is applied to directly the non-linear generalized Burgers-Huxley equation. Some examples are presented to show the ability of this method to solve the equation. It is clearly seen that numerical method is reasonably in good agreement with the exact solution.

\section{IMPLICIT EXPONENTIAL FINITE DIFFERENCE METHOD}

We rearrange Eq. (1) to obtain

$$
\frac{\partial u}{\partial t}=\beta u\left(1-u^{\delta}\right)\left(u^{\delta}-\gamma\right)-\alpha u^{\delta} \frac{\partial u}{\partial x}+\frac{\partial^{2} u}{\partial x^{2}}
$$

Dividing by $u$

$$
\frac{\partial \ln u}{\partial t}=\frac{1}{u}\left(\beta u\left(1-u^{\delta}\right)\left(u^{\delta}-\gamma\right)-\alpha u^{\delta} \frac{\partial u}{\partial x}+\frac{\partial^{2} u}{\partial x^{2}}\right)
$$

Using the finite difference approximations for derivatives Eq. (10) have been taken following form

$$
\begin{aligned}
U_{i}^{n+1}= & U_{i}^{n} \exp \left\{\frac { k } { U _ { i } ^ { n } } \left[\beta U_{i}^{n}\left(1-\left(U_{i}^{n}\right)^{\delta}\right)\left(\left(U_{i}^{n}\right)^{\delta}-\gamma\right)\right.\right. \\
& \left.\left.-\alpha\left(U_{i}^{n}\right)^{\delta}\left(\frac{U_{i+1}^{n+1}-U_{i-1}^{n+1}}{2 h}\right)+\left(\frac{U_{i+1}^{n+1}-2 U_{i}^{n+1}+U_{i-1}^{n+1}}{h^{2}}\right)\right]\right\}
\end{aligned}
$$

Eq. (11) is the implicit exponential finite difference method for solution of the generalized Burgers-Huxley equation. Where the solution domain is discretized into cells described by the nodes set $\left(x_{i}, t_{n}\right)$ in which $x_{i}=i h,(i=0,1,2, \ldots, N)$ and $t_{n}=$ $n k,(n=0,1,2, \ldots), h=\Delta x=\frac{1-0}{N}$ is the spatial mesh size and $k=\Delta t$ is the time step. Also $U_{i}^{n}$ denotes the finite difference approximation to the exact solution $u(x, t)$. Eq. (11) is system of nonlinear difference equations. Let us consider the nonlinear system of equations in the form

$$
\mathbf{F}(\mathbf{V})=\mathbf{0}
$$


where $\mathbf{F}=\left[f_{1}, f_{2}, \ldots, f_{N-1}\right]^{T}$ and $\mathbf{V}=\left[U_{1}^{n+1}, U_{2}^{n+1}, \ldots, U_{N-1}^{n+1}\right]^{T}$. Newton's method applied to Eq. (12) results in the following iteration:

1. Set $\mathbf{V}^{(0)}$, an initial guess.

2. Solved $\mathbf{V}^{(m+1)}=\mathbf{V}^{(m)}-J\left(\mathbf{V}^{(m)}\right)^{-1} \mathbf{F}\left(\mathbf{V}^{(m)}\right)$ for $m=0,1,2, \ldots$

where $J\left(\mathbf{V}^{(m)}\right)$ is the Jacobian matrix which is evaluated analytically. The solution at the previous time-step is taken as the initial estimate. The Newton's iteration at each time-step is stopped when $\left\|\mathbf{F}\left(\mathbf{V}^{(m)}\right)\right\|_{\infty} \leq 10^{-5}$. The convergence is generally obtained in two or three iterations. The accuracy of the method is measured in terms of the error norm defined by

$$
E=\left[\frac{\sum_{i=0}^{N}\left|u_{i}-U_{i}\right|^{2}}{\sum_{i=0}^{N}\left|u_{i}\right|^{2}}\right]^{\frac{1}{2}}
$$

\section{NUMERICAL RESULTS}

In this section, we obtain numerical solutions of the generalized Burgers-Huxley equation by implicit exponential finite difference method and exact solutions for problems. The accuracy of the proposed method is measured using the absolute error which defined by

$$
\left|u\left(x_{i}, t_{n}\right)-U\left(x_{i}, t_{n}\right)\right|
$$

All of the computational work is performed with $h=0.01$ and $k=0.0001$.

Problem 1. In Table 1,3,4 we present numerical and exact solutions for various values of $x, t$ and $\delta$ with $\alpha=1, \beta=1, \gamma=0.001$. The absolute errors obtained by the present method are compared with the other methods [2, 3, 7] in Table 2. All comparisons show that the present methods offer better results than the others.

Problem 2. Absolute errors for various values of $x, t$ and $\delta$ with $\alpha=0.1, \beta=$ $0.001, \gamma=0.0001$ showed in Table 5 .

Problem 3. Table 6 shows absolute errors for various values of $x, t$ and $\beta$ with $\alpha=1, \delta=1, \gamma=0.0001$.

Problem 4. Table 7 presents absolute errors for various values of $x, t$ and $\gamma$ with $\alpha=5, \beta=10, \delta=2$.

From all of the computed results is observed that values of the errors are very small. Also, it should be noted that the accuracy of the results decreased when $\delta$ and 
$\beta$ increased and the accuracy increased when $\gamma$ decreased. From comparisons of the numerical results with the exact solutions it is deduced that the proposed method gives highly accurate solutions. The rates of convergence of the method, computed using

$$
\text { rate }=\frac{\log \left(E^{h} / E^{h / 2}\right)}{\log (2)}
$$

where $E^{h}$ and $E^{h / 2}$ are the errors defined in Eq. (13) with the grid size $h$ and $h / 2$, respectively. Rate of convergence at $\delta=1$ and $t=1$ for the Problem 2 is shown in Table 8. From the table, we observe that the proposed method is second order accurate in space. From this table, it can be seen that errors approach to zero as the mesh refines, which shows that the scheme is consistent.

Table 1. Numerical solutions for $\delta=1$.

\begin{tabular}{clccc}
\hline$x$ & $t$ & Numerical Solution & Exact Solution & Absolute Error \\
\hline 0.1 & 0.05 & 0.000500022 & 0.000500037 & $1.544843 \mathrm{E}-08$ \\
& 0.1 & 0.000500040 & 0.000500063 & $2.258727 \mathrm{E}-08$ \\
& 1 & 0.000500478 & 0.000500512 & $3.372929 \mathrm{E}-08$ \\
& 5 & 0.000502477 & 0.000502511 & $3.373004 \mathrm{E}-08$ \\
& 10 & 0.000504975 & 0.000505009 & $3.372751 \mathrm{E}-08$ \\
& & & & \\
0.5 & 0.05 & 0.000500058 & 0.000500087 & $3.469057 \mathrm{E}-08$ \\
& 0.1 & 0.000500055 & 0.000500112 & $5.764000 \mathrm{E}-08$ \\
& 1 & 0.000500468 & 0.000500562 & $9.369800 \mathrm{E}-08$ \\
& 5 & 0.000502467 & 0.000502561 & $9.370081 \mathrm{E}-08$ \\
& 10 & 0.000504966 & 0.000505059 & $9.369382 \mathrm{E}-08$ \\
& & & & \\
0.9 & 0.05 & 0.000500122 & 0.000500137 & $1.544951 \mathrm{E}-08$ \\
& 0.1 & 0.000500140 & 0.000500162 & $2.258957 \mathrm{E}-08$ \\
& 1 & 0.000500578 & 0.000500612 & $3.373378 \mathrm{E}-08$ \\
& 5 & 0.000502577 & 0.000502611 & $3.373453 \mathrm{E}-08$ \\
& 10 & 0.000505075 & 0.000505109 & $3.373201 \mathrm{E}-08$ \\
\hline
\end{tabular}


Table 2. Comparison of the absolute errors for $\delta=1$.

\begin{tabular}{clcccc}
\hline$x$ & $t$ & Present Method & {$[2]$} & {$[3]$} & {$[7]$} \\
\hline 0.1 & 0.05 & $1.544843 \mathrm{E}-08$ & $1.93715 \mathrm{E}-07$ & $1.87406 \mathrm{E}-08$ & $1.87405 \mathrm{E}-08$ \\
& 0.1 & $2.258727 \mathrm{E}-08$ & $3.87434 \mathrm{E}-07$ & $3.74812 \mathrm{E}-08$ & $3.74813 \mathrm{E}-08$ \\
& 1 & $3.372929 \mathrm{E}-08$ & $3.87501 \mathrm{E}-06$ & $3.74812 \mathrm{E}-07$ & $3.74812 \mathrm{E}-07$ \\
& & & & & \\
0.5 & 0.05 & $3.469057 \mathrm{E}-08$ & $1.93730 \mathrm{E}-07$ & $1.87406 \mathrm{E}-08$ & $1.87405 \mathrm{E}-08$ \\
& 0.1 & $5.764000 \mathrm{E}-08$ & $3.87464 \mathrm{E}-07$ & $3.74812 \mathrm{E}-08$ & $1.37481 \mathrm{E}-08$ \\
& 1 & $9.369800 \mathrm{E}-08$ & $3.87531 \mathrm{E}-06$ & $3.74812 \mathrm{E}-07$ & $3.74813 \mathrm{E}-07$ \\
& & & & & \\
0.9 & 0.05 & $1.544951 \mathrm{E}-08$ & $1.93745 \mathrm{E}-07$ & $1.87406 \mathrm{E}-08$ & $1.87405 \mathrm{E}-08$ \\
& 0.1 & $2.258957 \mathrm{E}-08$ & $3.87494 \mathrm{E}-07$ & $3.74812 \mathrm{E}-08$ & $3.74813 \mathrm{E}-08$ \\
& 1 & $3.373378 \mathrm{E}-08$ & $3.87561 \mathrm{E}-06$ & $3.74812 \mathrm{E}-07$ & $3.74813 \mathrm{E}-07$ \\
\hline
\end{tabular}

Table 3. Numerical solutions for $\delta=2$.

\begin{tabular}{clccc}
\hline$x$ & $t$ & Numerical Solution & Exact Solution & Absolute Error \\
\hline 0.1 & 0.05 & 0.022362607 & 0.022364010 & $1.402926 \mathrm{E}-06$ \\
& 0.1 & 0.022364804 & 0.022366855 & $2.051046 \mathrm{E}-06$ \\
& 1 & 0.022414941 & 0.022417997 & $3.056210 \mathrm{E}-06$ \\
& & & & \\
0.5 & 0.05 & 0.022362802 & 0.022365952 & $3.150237 \mathrm{E}-06$ \\
& 0.1 & 0.022363563 & 0.022368796 & $5.233912 \mathrm{E}-06$ \\
& 1 & 0.022411444 & 0.022419934 & $8.490077 \mathrm{E}-06$ \\
& & & & \\
0.9 & 0.05 & 0.022366491 & 0.022367893 & $1.402867 \mathrm{E}-06$ \\
& 0.1 & 0.022368687 & 0.022370738 & $2.051080 \mathrm{E}-06$ \\
& 1 & 0.022418815 & 0.022421871 & $3.056440 \mathrm{E}-06$ \\
\hline
\end{tabular}


Table 4. Numerical solutions for $\delta=3$.

\begin{tabular}{clccc}
\hline$x$ & $t$ & Numerical Solution & Exact Solution & Absolute Error \\
\hline 0.1 & 0.05 & 0.079382156 & 0.079390945 & $8.789379 \mathrm{E}-06$ \\
& 0.1 & 0.079397433 & 0.079410279 & $1.284676 \mathrm{E}-05$ \\
& 1 & 0.079737642 & 0.079756666 & $1.902469 \mathrm{E}-05$ \\
& & & & \\
0.5 & 0.05 & 0.079377402 & 0.079397138 & $1.973612 \mathrm{E}-05$ \\
& 0.1 & 0.079383686 & 0.079416470 & $3.278338 \mathrm{E}-05$ \\
& 1 & 0.079709947 & 0.079762802 & $5.285447 \mathrm{E}-05$ \\
& & & & \\
0.9 & 0.05 & 0.079394543 & 0.079403331 & $8.788219 \mathrm{E}-06$ \\
& 0.1 & 0.079409813 & 0.079422659 & $1.284610 \mathrm{E}-05$ \\
& 1 & 0.079749911 & 0.079768936 & $1.902522 \mathrm{E}-05$ \\
\hline
\end{tabular}

Table 5. Absolute errors for various values of $x, t$ and $\delta$.

\begin{tabular}{cccccc}
\hline$x$ & $t$ & $\delta=1$ & $\delta=2$ & $\delta=4$ & $\delta=8$ \\
\hline 0.1 & 0.2 & $1.561971 \mathrm{E}-13$ & $3.838021 \mathrm{E}-11$ & $1.277132 \mathrm{E}-9$ & $1.743995 \mathrm{E}-8$ \\
& 0.5 & $1.770063 \mathrm{E}-13$ & $4.349335 \mathrm{E}-11$ & $1.447275 \mathrm{E}-9$ & $1.976331 \mathrm{E}-8$ \\
& 0.8 & $1.780854 \mathrm{E}-13$ & $4.375852 \mathrm{E}-11$ & $1.456099 \mathrm{E}-9$ & $1.988374 \mathrm{E}-8$ \\
& & & & & \\
0.5 & 0.2 & $4.238227 \mathrm{E}-13$ & $1.041405 \mathrm{E}-10$ & $3.465347 \mathrm{E}-9$ & $4.732128 \mathrm{E}-8$ \\
& 0.5 & $4.911626 \mathrm{E}-13$ & $1.206870 \mathrm{E}-10$ & $4.015944 \mathrm{E}-9$ & $5.483986 \mathrm{E}-8$ \\
& 0.8 & $4.946546 \mathrm{E}-13$ & $1.215451 \mathrm{E}-10$ & $4.044498 \mathrm{E}-9$ & $5.522962 \mathrm{E}-8$ \\
& & & & & \\
0.9 & 0.2 & $1.561971 \mathrm{E}-13$ & $3.838038 \mathrm{E}-11$ & $1.277131 \mathrm{E}-9$ & $1.743996 \mathrm{E}-8$ \\
& 0.5 & $1.770063 \mathrm{E}-13$ & $4.349352 \mathrm{E}-11$ & $1.447276 \mathrm{E}-9$ & $1.976332 \mathrm{E}-8$ \\
& 0.8 & $1.780854 \mathrm{E}-13$ & $4.375869 \mathrm{E}-11$ & $1.456099 \mathrm{E}-9$ & $1.988376 \mathrm{E}-8$ \\
\hline
\end{tabular}


Table 6. Absolute errors for various values of $x, t$ and $\beta$.

\begin{tabular}{ccccc}
\hline$x$ & $t$ & $\beta=1$ & $\beta=10$ & $\beta=100$ \\
\hline 0.1 & 0.2 & $2.959033 \mathrm{E}-10$ & $4.142647 \mathrm{E}-9$ & $4.662398 \mathrm{E}-8$ \\
& 0.5 & $3.353246 \mathrm{E}-10$ & $4.694542 \mathrm{E}-9$ & $5.283266 \mathrm{E}-8$ \\
& 0.8 & $3.373690 \mathrm{E}-10$ & $4.723160 \mathrm{E}-9$ & $5.314880 \mathrm{E}-8$ \\
& & & & \\
0.5 & 0.2 & $8.029042 \mathrm{E}-10$ & $1.124065 \mathrm{E}-8$ & $1.265096 \mathrm{E}-7$ \\
& 0.5 & $9.304752 \mathrm{E}-10$ & $1.302665 \mathrm{E}-8$ & $1.466032 \mathrm{E}-7$ \\
& 0.8 & $9.370912 \mathrm{E}-10$ & $1.311926 \mathrm{E}-8$ & $1.476294 \mathrm{E}-7$ \\
& & & & \\
0.9 & 0.2 & $2.959071 \mathrm{E}-10$ & $4.142698 \mathrm{E}-9$ & $4.662452 \mathrm{E}-8$ \\
& 0.5 & $3.353291 \mathrm{E}-10$ & $4.694604 \mathrm{E}-9$ & $5.283328 \mathrm{E}-8$ \\
& 0.8 & $3.373735 \mathrm{E}-10$ & $4.723223 \mathrm{E}-9$ & $5.314937 \mathrm{E}-8$ \\
\hline
\end{tabular}

Table 7. Absolute errors for various values of $x, t$ and $\gamma$.

\begin{tabular}{ccccc}
\hline$x$ & $t$ & $\gamma=10^{-3}$ & $\gamma=10^{-4}$ & $\gamma=10^{-5}$ \\
\hline 0.1 & 0.2 & $2.075083 \mathrm{E}-5$ & $6.580584 \mathrm{E}-7$ & $2.081548 \mathrm{E}-8$ \\
& 0.5 & $2.339464 \mathrm{E}-5$ & $7.453542 \mathrm{E}-7$ & $2.358742 \mathrm{E}-8$ \\
& 0.8 & $2.340002 \mathrm{E}-5$ & $7.494830 \mathrm{E}-7$ & $2.372992 \mathrm{E}-8$ \\
& & & & \\
0.5 & 0.2 & $5.633069 \mathrm{E}-5$ & $1.785646 \mathrm{E}-6$ & $5.648063 \mathrm{E}-8$ \\
& 0.5 & $6.495332 \mathrm{E}-5$ & $2.068347 \mathrm{E}-6$ & $6.545147 \mathrm{E}-8$ \\
& 0.8 & $6.503520 \mathrm{E}-5$ & $2.081902 \mathrm{E}-6$ & $6.591322 \mathrm{E}-8$ \\
& & & & \\
0.9 & 0.2 & $2.076000 \mathrm{E}-5$ & $6.580875 \mathrm{E}-7$ & $2.081557 \mathrm{E}-8$ \\
& 0.5 & $2.340657 \mathrm{E}-5$ & $7.453920 \mathrm{E}-7$ & $2.358754 \mathrm{E}-8$ \\
& 0.8 & $2.341208 \mathrm{E}-5$ & $7.495213 \mathrm{E}-7$ & $2.373004 \mathrm{E}-8$ \\
\hline
\end{tabular}


Table 8. Rate of convergence for $\delta=1$ at $t=1$.

\begin{tabular}{lc}
\hline$N$ & rate \\
\hline 2 & - \\
4 & 0.175608438 \\
8 & 0.078691220 \\
16 & 0.041403087 \\
32 & 0.021266315 \\
64 & 0.011014546 \\
\hline
\end{tabular}

\section{CONCLUSION}

In this paper, we have defined a new implicit exponential finite difference method for solving the generalized Burgers-Huxley equation. Numerical solutions for different test problems are given using tables. According to the results presented in these tables, the present method offer high accuracy for the numerical solutions of the nonlinear generalized Burgers-Huxley equation. In the other hand, as can be seen from Table 2, results obtained by the implicit exponential finite difference scheme has better than results obtained from the other numerical schemes.

\section{REFERENCES}

[1] X. Y. Wang, Z. S. Zhu, Y. K. Lu, Solitary wave solutions of the generalized Burgers-Huxley equation, J. Phys. A: Math. Gen. 23 (1990) 271-274.

[2] H. N. A. Ismail, K. Raslan, A. A. Abd-Rabboh, Adomian decomposition method for Burgers-Huxley and Burgers-Fisher equations, Appl. Math. Comput. 159 (2004) 291-301.

[3] I. Hashim, M. S. M. Noorani, M. R. Said Al-Hadidi, Solving the generalized Burgers-Huxley Equation using the Adomian decomposition method, Math. Comput. Model. 43 (2006) 1404-1411.

[4] M. Javidi, A numerical solution of the generalized Burger's-Huxley equation by pseudospectral method and Darvishi's preconditioning, Appl. Math. Comput. 175 (2006) 1619-1628.

[5] M. Javidi, A numerical solution of the generalized Burger's-Huxley equation by spectral collocation method, Appl. Math. Comput. 178 (2006) 338-344.

[6] M. T. Darvishi, S. Kheybari, F. Khani, Spectral collocation method and Darvishi's preconditionings to solve the generalized Burgers-Huxley equation, Commun. Nonlinear Sci. Numer. Simul. 13 (2008) 2091-2103.

[7] B. Batiha, M. S. M. Noorani, I. Hashim, Application of variational iteration method to the generalized Burgers-Huxley equation, Chaos Soliton Fract. 36 (2008) 660-663.

[8] M. Sari, G. Gürarslan, Numerical solutions of the generalized Burgers-Huxley equation by a differential quadrature method, Math. Probl. Eng. 2009, doi: 10.1155/2009/370765.

[9] A. J. Khattak, A computational meshless method for the generalized Burger's-Huxley equation, Appl. Math. Model. 33 (2009) 3218-3729. 
[10] M. Javidi, A. Golbabai, A new domain decomposition algorithm for generalized Burger's-Huxley equation based on Chebyshev polynomials and preconditioning, Chaos Soliton Fract. 39 (2009) 849857.

[11] J. Biazar, F. Mohammadi, Application of differential transform method to the generalized BurgersHuxley equation, Appl. Appl. Math. 5 (2010) 1726-1740.

[12] A. G. Bratsos, A fourth order improved numerical scheme for the generalized Burgers-Huxley equation, American J. Comput. Math. 1 (2011) 152-158.

[13] M. Dehghan, B. N. Saray, M. Lakestani, Three methods based on the interpolation scaling functions and the mixed collocation finite difference schemes for the numerical solution of the nonlinear generalized Burgers-Huxley equation, Math. Computer Model. 55 (2012) 1129-1142.

[14] İ. Çelik, Haar wavelet method for solving generalized Burgers-Huxley equation, Arab J. Math. Sci. 18 (2012) 25-37.

[15] M. El-Kady, S. M. El-Sayed, H. E. Fathy, Development of Galerkin method for solving the generalized Burger's Huxley equation, Math. Probl. Eng. 2013, doi: 10.1155/2013/165492.

[16] A. M. Al-Rozbayani, Discrete Adomian decomposition method for solving Burger's-Huxley Equation, Int. J. Contemp. Math. Sci. 8 (2013) 623-631.

[17] R. C. Mittal, A. Tripathi, Numerical solutions of generalized Burgers-Fisher and generalized BurgersHuxley equations using collocation of cubic B-splines, Int. J. Comput. Math. 5 (2015) 1053-1077.

[18] İ. Çelik, Chebyshev Wavelet collocation method for solving generalized Burgers-Huxley equation, Math. Meth. Appl. Sci. 2015, doi: 10.1002/mma.3487

[19] M. C. Bhattacharya, An explicit conditionally stable finite difference equation for heat conduction problems, Int. J. Num. Meth. Eng. 21 (1985) 239-265.

[20] M. C. Bhattacharya, Finite difference solutions of partial differential equations, Commun. Appl. Numer. Meth. 6 (1990) 173-184.

[21] R. F. Handschuh, T. G. Keith, Applications of an exponential finite-difference technique, Numer. Heat Transfer. 22 (1992) 363-378.

[22] A. R. Bahadır, Exponential finite-difference method applied to Korteweg-de Vries equation for small times, Appl. Math. Comput. 160 (2005) 675-682.

[23] B. Inan, A. R. Bahadir, Numerical solution of the one-dimensional Burgers equation: Implicit and fully implicit exponential finite difference methods, Pramana J. Phys. 81 (2013) 547-556.

\author{
Bilge İnan \\ Department of Mathematics, Faculty of Muallim Rıfat Education, Kilis 7 Aralık \\ University, Kilis, Turkey \\ bilgeinan@kilis.edu.tr
}

\author{
Ahmet Refik Bahadir \\ Department of Mathematics, Faculty of Arts and Science, İnönü University, \\ Malatya, Turkey \\ refik.bahadir@inonu.edu.tr
}

